\title{
Barriers to technology translation in magnetic resonance to medicine
}

\author{
Paul A. Bottomley ${ }^{1}[$ \\ Received: 16 August 2021 / Revised: 18 August 2021 / Accepted: 19 August 2021 / Published online: 26 August 2021 \\ (c) European Society for Magnetic Resonance in Medicine and Biology (ESMRMB) 2021
}

Journals devoted to magnetic resonance (MR) in biomedicine such as this one, brim with research touting methodological advances, both significant and nuanced. While the advantages and potential impact of each study are important considerations for publication, a paper that is not novel is generally not publishable. Research grants-our bread and butter-are awarded based on similar criteria but shower much larger material benefits on successful applicants and their institutions. Day-in and day-out, journal pages need to be filled and grants pushed out of the doors of willing sponsors, all to feed the world-wide scientific research enterprise for the good of homo sapiens. This we know.

But the system is not perfect. The demand for novel fodder for journals, as well as for research grants to deliver solutions to problems that were supposed to have been solved in the last $1,2,5,10$, or 20 rounds of funding, often produces "new" methods that seem...deja-vu. There are works-in-progress on the measurement of measures that are themselves work-in-progress in showing added value; old methodology performed with new operating parameters or extra Teslas; studies of cells or mice or of MR labels whose connection to the discovery of new scientific factoids or medical advances that can be applied to people, often seem as remote as ever. This crucible in which we work, we know as well.

The commentary discusses some of the barriers to the bench-tobedside translation of magnetic resonance (MR) technologies, illustrated by a number of examples.

Paul A. Bottomley

bottoml@mri.jhu.edu; pbottom1@jh.edu

1 Division of MR Research, Department of Radiology and Radiological Science, Johns Hopkins University, Baltimore, MD, USA

\section{The conflict of conflict of interest}

Set against the desirable outcome of such endeavors-the bench to bedside proofing of the pudding - is an ever growing regulatory minefield. Outside reviews and approvals for safety; conflicts-of-interest (COIs); the race and gender of participants; and more recently in the USA, government permission for international collaborations and for non-citizen scientists to work on a project, even when they are the ones championing it. The latter is particularly odious. One can be fired or banned for practicing centuries-old traditions of scientific collaboration without such approvals. Sadly, no one or institution stands against this modern-day Inquisition. No surprise if the upshot of regulatory burden is to reduce the likelihood of the extraordinary translating to the clinic. ${ }^{1}$ Or even if it increases the likelihood of translating technical leadership to those countries where the would-be collaborators who are being discriminated against, reside; or where such burdens are less. In this context, MRI research studies of phantoms, mice, cells and MR sequences are more "regulatory safe" in the sense that they are better suited to minimizing the likelihood of raising the heckles of the Inquisitors of COI and safety, by avoiding anything that touches humans - or at least anything beyond the built-in safety mechanisms installed on modern clinical MRI scanners. But even these applications usually require collaborative pre-agreements with scanner companies for software and hardware access, that in turn require further institutional approvals that can take years.

Maybe I exaggerate the regulatory burden. I do remember that MRI was born and tested on humans before most of the regulatory barriers descended. Institutional Review Boards (IRBs) did not exist at Nottingham or Aberdeen in 1975. Yet risk did not run rampant. The investigators were still responsible for ensuring safety (as they still are today). This began with analyses of safety issues and electrical practice that was in truth, far beyond the technical expertise of any

\footnotetext{
1 The highly accelerated development of COVID-19 vaccine is an exception illustrating that the regulatory minefield can be surmounted if need and financial resources are great.
} 
existing regulatory body at that time. Human studies invariably started with self-testing. When patient studies began, it was the safety assessment and judgement of the physicians in collaboration with the MRI investigators-with the subject's permission - that held sway. And yes, the Nottingham and Aberdeen investigators had patents licensed to for-profit entities (for the purpose of potentially making MRI scanners) and yes, many of these investigators consulted directly with commercial imaging companies as well. In the USA, myself and others were employed by $G E$ and by other companies, including Technicare, Diasonics and Raymond Damadian's FONAR. Many other MRI investigators in Europe had patents that were licensed, had potential for personal gain or loss from their various commercial dealings, and their scientists directed human MRI studies as well.

Today, these would represent dire COIs in the USA and elsewhere. Imagine if Peter Mansfield, Waldo Hinshaw, Bill Moore, Bill Edelstein or Jim Hutchison who had MRI patents, were not allowed to direct or perform those initial human MRI studies on scanners that they had built. Take a hard look at the dubious animal and vegetable MRIs of the time. Would MRI exist today if not for those earliest experiments and feedback from human studies performed by those "conflicted" investigators? Today, COI is a significant barrier to champions of translational research. "Non-interested parties" are supposed to take charge. But who in their right mind, would ask a non-interested party to perform any laboratory research? The translation of new ideas often fails without a champion, while the "conflict" of COI implies at least two different interests. At the birth of MRI, there was just one interest: reduction-to-practice ...the translation of MRI to the clinic. Today our regulatory masters are more obsessed about whether a researcher might benefit from a successful translation, than providing support to facilitate it moving forward.

Indeed, COI reviews are fraught with hypocrisy. Our university's training module, ${ }^{2}$ defines: "A conflict of interest is a situation in which an individual (investigator/research employee) is in a position to exploit a situation for personal gain". By this definition, the entire livelihood of a research scientist-employment, salary, benefits, promotion, bonuses and any derived kudos-is one big COI, being almost entirely dependent on the publishing and grant-generating output of the research. Against one's livelihood and career, minor consulting income; future benefits from a patent that may or may not be granted in a future year, after which it may or

\footnotetext{
${ }^{2}$ Mandated and tested annually at our institution, along with a battery of other courses mandated for continuance as a researcher.

${ }^{3}$ We are currently not allowed to accept pens lest someone see a company name on them (another hypocrisy given the prominent display of manufacturer's names on virtually all equipment at the institu-
}

may not be licensed; a free lunch; or even a free pen from a vendor, ${ }^{3}$ are miniscule benefits by comparison. But nowadays it seems that only the miniscule is viewed as the COI. Is there any other profession that accepts as a tenet that no personal gain can result from its practice? Even the priest, sworn to live humbly, benefits from cash funds collected directly from parishioners, to whom no COI declarations to the givers (= sponsors) are required. Oddly, it is not even a task of COI evaluation committees to root-out bad or corrupt science. That is the forte of peer review and of other scientist's efforts at reproducing published findings, and of committees on scientific misconduct that form when the need arises. So what value is added to science by COI review?

And do failures of translation due to COI, actually happen? While case histories and circumstances certainly differ, it is noticeable that the introduction of most medical imaging modalities occurred prior to modern regulatory curtainfalls: X-ray, radionuclide, CAT, ultrasound, PET-as well as MRI, which just managed to sneak in. So what new imaging modalities have come after MRI since the 1980s? Of course, it is possible that the universe has closed-shop on fundamentally-new medical imaging modalities, that there are just no more to be had. On the other hand, who could doubt that the regulation of what is safe today would seriously impede if not preclude, the clinical translation of some of those older imaging modalities if they had the misfortune of materializing today for the very first time.

On a personal note, I was recently involved in developing a minimally-invasive "MRI endoscopy" technology with $\mathrm{NIH}$ grant support. I wanted to translate it to humans in a renewal grant. The fact that my university applied for a patent-as required by NIH rules-and licensed it, created a COI for the human work. Being unable to perform the human study at my institution, I arranged to perform initial human studies by a group with an interventional champion in London UK, as a work-around. This was foiled during the grant's review where it was advised that we should not be doing human translation and that should be done by industry. I removed that aim and the grant was funded. I cannot say whether this translation was killed by $\mathrm{COI}$ or by grant review, but COI was certainly a factor. ${ }^{4}$

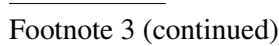

tion, not to mention the logos of vendors who rent space therein or the $F E D E X$ boxes).

${ }^{4}$ Although I also had non-grant funds that could support the work, COI rules and their impact on IRB approval were/remain major deterrents to translation, which to date has not been visited on humans. 


\section{Death by exclusivity}

On the industry side of the equation, I witnessed first-hand $G E$ 's stunning translation of our 1.5 Tesla MRI effort into a product via a brand-new factory churning-out hundreds of MRI scanners in the early 1980s. ${ }^{5}$ That was not funded by grants and our team and I were $G E$ employees with our patents (owned by $G E$ ). Bench-to-clinical product translation took about a year, and the MRI product "widget" cost millions of dollars a pop. It was an incredible demonstration of the brute-force power of money to translate a new technology to the clinic. On a global scale, the COVID-19 vaccine development is an even better example of the power of money ${ }^{1}$.

But money may also have an opposite effect, even for the same reason and even in our field. A key driver of $G E$ 's effort in 1.5 Tesla MRI was threat. The dual threats posed to its existing X-ray CT business and of being left-in-the-dust by their competitors who were already marketing low-field $\left(\leq 0.3\right.$ Tesla) MRI products at the time $e^{5}$. Twenty years after that -at the 2001 ISMRM meeting in Glasgow, hyperpolarized helium $\left({ }^{3} \mathrm{He}\right)$ was the new thing, showing great clinical promise for assessing lung function; and by 2003, researchers at Amersham PLC had developed a method for hyper-polarizing carbon $\left({ }^{13} \mathrm{C}\right)$, as well. So when $G E$ bought both Amersham in a deal announced late in 2003, and Magnetic Imaging Technologies Inc, a Duke University start-up to translate hyperpolarized ${ }^{3} \mathrm{He}$ MRI to the clinic, the hope was for a hyperpolarization product that could provide MRI with a sensitivity approaching that of PET, complete with ${ }^{13} \mathrm{C}$-labelled metabolites and no ionizing radiation. That did not happen (fast). After intellectual property was secured, the incentive for human translation seemed to wane. Indeed, human ${ }^{13} \mathrm{C}$ studies were not allowed on the first experimental systems and user's down-stream patent rights were limited as well. Happily, translation of the hyperpolarized ${ }^{13} \mathrm{C}$ work to humans did begin some years ago. ${ }^{6}$ One wonders about coincidences between the time-lag for human studies, the 17 year or 20 year life-spans of USA and EU patents, or indeed the 17 year cycle of the Great Eastern Brood cicada-plague that was in full-sing in north-east America this summer. How

\footnotetext{
${ }^{5}$ Bottomley PA. On the origins of localized NMR: view from an accomplice. In: Bydder GM, Young IR, Paley M, eds. The development of magnetic resonance imaging and spectroscopy, MRIS history UK. https://mrishistory.org.uk. 2019; Vol.1.

${ }^{6}$ GE launched Research Circle Technology Inc in 2011 to accommodate Amersham technology (Ardenkjaer-Larsen et al, PNAS 2003; 10010158-10163); a first human study appeared in 2013 (Nelson SJ et al.; Sci Trans Med 2013; 5: 198); SPINLAB, a hyper-polarizing system was introduced at the Milan ESMRMB meeting in 2014; by 2019, about 10 sites were said to be performing human studies (Zhen $\mathrm{J}$ et al. Hyperpolarized ${ }^{13} \mathrm{C}$ MRI: state of the art and future directions. Radiol 2019; 291: 273-284).
}

much further along would the engineering and applications of this novel technology and its prospects for clinical translation be, if the human work had begun a decade or so earlier?

One might blame industry for the delay, but academia did not seem in much rush to translate the technology to humans either. IP issues would not have prevented go-it-alone construction of a research hyper-polarizer for human use by competent MR investigators. Perhaps I am mistaken, but the hyperpolarization technology seems less of a heavy-lift than the building of whole-body MRI scanners in universities decades earlier, and the expertise required for fabricating and delivering time-sensitive substrates for human work is akin to that done routinely for PET (the complications of cryogenics replacing those of ionizing radiation). Was it a lack of translational champions? .... a failure of funding agencies to support translation (akin to my endoscopy experience)? ...or did building a device to generate non-toxic ${ }^{13} \mathrm{C}$-labelled versions of endogenous metabolites for human use, require too many regulatory hurdles to bother with? I cannot say.

I do know that today, industry also faces as harsh a regulatory environment as ever. This can be fatal for small startup companies trying to translate new medical technologies from universities to clinics. In the USA, that process has long been dubbed Death Valley. As another personal example, I was involved with the development of MRI antennas as catheters, a predecessor of the MRI endoscopy project noted above. That work was also born of NIH funding, and a small company was started with the university as partner, to take the technology to the clinic. This was the late 1990s when interventional MRI was the new thing. The start-up was funded and survived Death Valley to obtain FDA clearance for prostate, urethral and intra-vascular devices. But then it signed an exclusive deal with a large MRI scanner maker to market them. The agreement specified devices to be delivered with revenue back to the start-up. Devices were delivered, but no revenue streamed. It was as if the agreement removed a threat to the larger company so that little further effort was required. The start-up was forced to hibernate. Another case of translational death by exclusive agreement $?^{7}$...or just a product failure to launch?

\section{Failure to launch}

Of course $G E$ had its own failure o' translation in interventional MRI. They developed a whole new 0.5 Tesla MRI system for performing image-guided therapy (MRT), with an open "walk-in" bore. This was born of an exemplary

\footnotetext{
$\overline{7}$ Fortunately the company lived and is now publicly traded.
} 
academic collaboration initiated with the late Ferenc Jolesz at Harvard and my old group at $G E$ 's research center in Schenectady NY which made the hardware. ${ }^{8}$ The system was marketed by GE to mostly non-interventional MRI customers, and a handful were sold. However, a clinical revenue stream was needed to pay the bills. While clinical interventional MRI procedures did not materialize fast enough, regular clinical MRI offered an immediate fix to fill the gaping holes in schedules. Alas, the open 0.5 Tesla system could not compete with the standard-of-care provided by the customer's on-site 1.5 Tesla systems used for regular MRI. The product could not pay for itself and went away surprisingly fast.

This death of yet another open-magnet low Tesla MRI system-even though its field was higher than most of the low-field offerings of the early 1980s that met a similar fate-is a sobering warning to the re-awakened interest in low-field systems today, at least for clinical imaging in Europe and North America. But low Tesla alone does not always predict outcome either: within a year of $G E$ introducing their 1.5 Tesla system, whole body 2.0 Tesla systems were offered by at least one other major competitor. These promptly failed. In the interim years, open whole-body 0.3 to 1.0 Tesla systems have come and many have gone: today they represent perhaps $6 \%$ of western markets [1]. Meanwhile, 4.0 Tesla systems installed in a few leading academic facilities in the 1990s have nearly all vanished, despite the strength of their engineering support.

Indeed, modern 1.5, 3.0 and 7.0 Tesla systems only exist in significant numbers today because of the herculean effort of scanner manufacturers to engineer them into real, superior-performing, products. The manufacturer's efforts, in my view, are under-recognized. Sure, they get paid (a COI). So do users (not a COI). As alluded to above, the vast majority of MRI researchers work on projects that do not and cannot push the scanners beyond the limits of their built-in versatility. We researchers piggy-back onto the manufacturer's in-built safety mechanisms and their regulatory product approvals, whenever we request IRB and animal welfare committee approvals for our scanning protocols. In doing so, we side-step processes that would otherwise severely cripple if not end, most of our research on methodological development. But scanner limitations are still real. If, for example, you are an academic protagonist of nonlinear gradients or new designs for silent gradient systems (in vacuums), you'll probably have to make a whole MRI system and show how it is so much better than the scanner de jour if you ever want to see it translate. This is a much higher bar than publishing a paper on a new RF coil design or pulse sequence.

\footnotetext{
${ }^{8}$ Schenck JF, Jolesz FA, Roemer PB et al. Superconducting openconfiguration MR imaging system for image-guided therapy. Radiol 1995; 195: 805-814.
}

In all cases, the end-point of technology translation is not just demonstrating performance in one's own lab but its adoption into $>>1$ research or clinical settings. And of course you can succeed in one but not the other. For example, consider sodium $\left({ }^{23} \mathrm{Na}\right) \mathrm{MRI}$ and phosphorus, proton and ${ }^{13} \mathrm{C}$ MRS. In the two-score years since the first human studies in the 1980s, their ongoing applications have generated huge numbers of research papers that signify successful translation in research settings. However today, I still cannot get a clinical ${ }^{23} \mathrm{Na}$ or a clinical metabolic MRS scan at our local MRI-equipped hospital in Columbia MD. As information-rich as these technologies may be, that type of clinical translation has not yet materialized. Establishing both an added clinical value and an integrated clinical product that addresses the peccadillos of low-SNR nuclei to deliver robust clinical outcomes, still needed for regulatory approval and reimbursement as endpoints of clinical translation.

\section{Endpoints}

In closing, bench-to-bedside translation of any MR technology is a super-heavy lift for individual investigators and their research teams in academia. As evidenced by the many examples of failure to launch, it is hard enough to prove the merit-based requirements of value, efficacy and safety which have always been key to successful translation. Understandably perhaps, the typical scientist's natural instincts to stick to the science, has left a bit of a void between the leading edge of research output, and the passing of it along for human benefit. Into that void, administrators and regulators have marched with batteries of regulatory hurdles. These include non-scientific agendas on race (racial quotas for research participants that are unrelated to scientific hypotheses being tested), political xenophobia (vetting of foreign nationals and collaborations based on country-of-origin and not scientific expertise), and the moralist view that innovators must not benefit from their effort (or receive benefits that don't flow through their institution) noted above.

Challenging the forces of non-science emanating from institutions, sponsors and governments, risks job-loss, loss of research support and thence loss of livelihood, and is basically impossible for individual investigators. A purge of the un-science would at least require an assertive, organized effort from protagonist professional societies like ESMRMB, ISMRM and national level scientific academies. Meanwhile, regulatory encroachment on scientific productivity is not abating. In recent years, the USA's NIH has attempted to categorize all fMRI studies as clinical trials which would subject them to additional review and reporting requirements. This year, a declaration of "in kind support" is being demanded of investigators, as if a new kind of sin has been discovered for the confessional. And to feed the 
demand for even more regulatory non-science, the proportion of administrators employed by universities, steadily rising for decades, now commonly exceeds that of faculty, at least in the USA and the UK. ${ }^{9}$

Yes, "Centers of Translational Research" do exist and are often linked to universities. Ironically, they tend to be forprofit to conduct clinical trials for biomedical, device and pharmaceutical industries, which are their main customers (COI allows Centers to benefit financially from translation, but not the Creators of the thing being translated). While I cannot generalize, I have yet to see such Centers actually $h e l p$ with the clinical translation of an investigator's laboratory-tested advance in the field of MR research. They could well do so, but that would require financial support.

Currently, you either patent and license your technology to one or more of the major MRI companies and hope it shows up in a scanner in a few years; or you create your own start-up company. Both routes have successes that show that these mechanisms can work. Recent(-ish) technology transfers from universities to large imaging companies include: compressed SENSE, which translated all the way to the clinic; and brain fiber-track mapping, diffusion MRI, CEST, and MR-fingerprinting which are at least major hits in research settings. Examples of existing MRI technology companies that have evolved from universities include RAPID Biomedical from the University of Wurzburg; Perspectum diagnostics from Oxford University; and ClearPoint Neuro (formerly MRI Interventions) from Johns Hopkins University. There are many more examples. In the USA small business grants are quite well supported but NIH grants that include translation can easily run aground on scoring for novelty and innovation, which are typically interpreted as passé by the time a technology is ready to translate.

Regardless of which of the many hurdles are fatal to the translation of promising university-born innovations, too many die on the bench or in the limbo-lands between cell, animal and human studies. That loss represents a tremendous cost in precious resources. It's not just the cost of the original research plus the ever-inflating cost of regulators needed to distract the research; but also the loss of potential benefit to humanity whenever a great idea fails because there are no funds for translation, or because the hurdles are, or are perceived as being, too large to be bothered with. Medicine has an oath to "do no harm". For our field, a strong dose of "help not hinder" could ease some barriers to technology translation.

The above is my opinion and does not represent that of the editor, the editorial board, the journal, the ESMRMB or any entities mentioned herein who may have different takes on the subject matter. I thank Peter van Zijl for his helpful comments.

Paul A Bottomley.

August 2021.

\section{References}

1. Sarracanie M, Salameh N (2020) Low-field MRI: How low can we go? A fresh view on an old debate. Front Phys. https://doi.org/ 10.3389/fphy.2020.00172

Publisher's Note Springer Nature remains neutral with regard to jurisdictional claims in published maps and institutional affiliations.

\footnotetext{
9 Spicer A. Universities are broke so let's cut the pointless admin and get back to teaching. The Guardian. Aug 21 2017. https://www.thegu ardian.com/commentisfree/2017/aug/21/universities-broke-cut-point less-admin-teaching.

Staddon J. Administrative bloat: where does it come from and what is it doing? James G Martin Center for Academic Renewal. Jun 19 2019. https://www.jamesgmartin.center/2019/06/administrative-bloatwhere-does-it-come-from-and-what-is-it-doing/.

https://scaleatucla.weebly.com/ucla-senior-management-growth-incomparison-to-faculty-and-students-1993-2014.html. For a fuller list, Google "More administrators than faculty at universities".
} 